ISSN electrónico: 2172-9077

DOI: https://doi.org/10.14201/fjc202021263266

\title{
PEQUEÑO FORMATO SIN LÍMITES: EL NUEVO CORTOMETRAJE
}

\section{Small without Limit: Short Film}

Dra. María LOIS CAMPOS

Universidad de Vigo. Facultad de Bellas Artes (Pontevedra). España

E-mail: demarialois@gmail.com

(iD) https://orcid.org/0000-0002-2051-6288

Fecha de recepción de la reseña: 04/07/2020

Fecha de aceptación definitiva: 22/07/2020

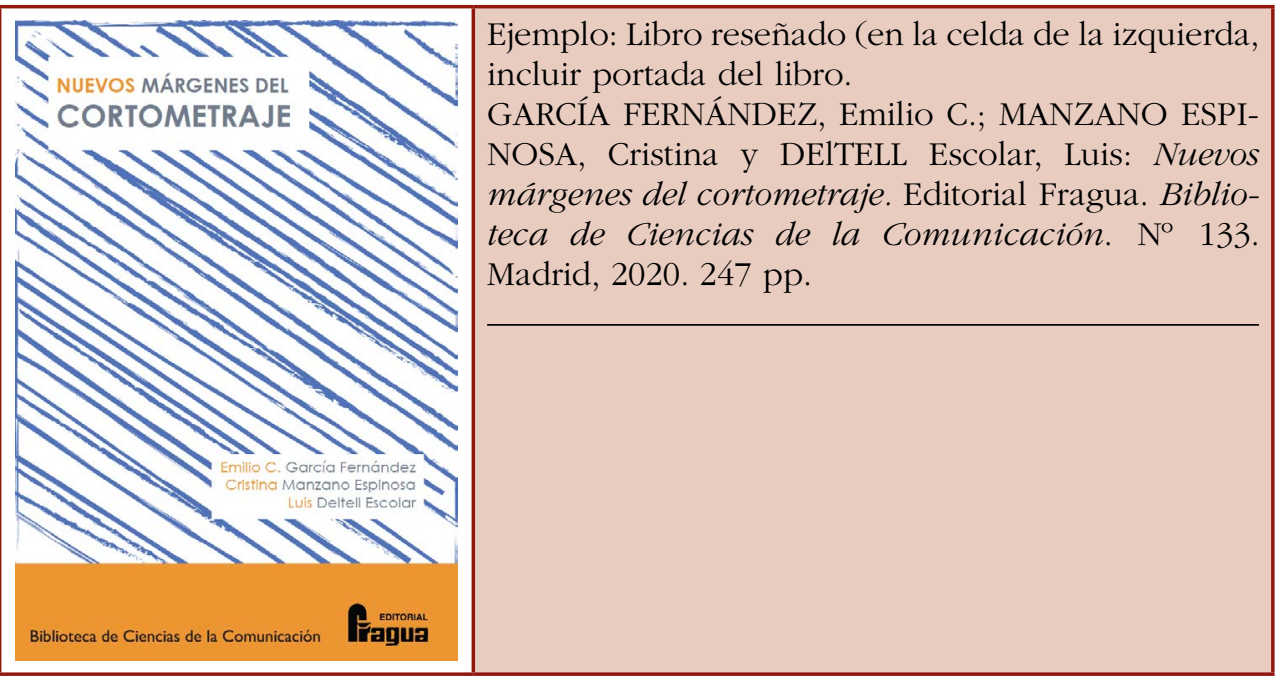

\section{Introducción}

En el complejo año de 2020 la producción científica en torno al audiovisual no se detuvo. Durante el estado de alarma por la COVID-19, han surgido diversos libros sobre el cine. Entre ellos uno que aborda el pequeño formato: Nuevos márgenes del cortometraje. El texto resulta interesante por su triple propuesta ya que aborda espacios poco estudiados. Su original portada basadas en líneas azules ya invita al lector a comprender que el cortometraje no se trata de una enunciación cuadriculada 
sino libre y plural. Así, esta imagen ejemplifica la libertad de los nuevos márgenes mediante líneas diagonales dinámicas que se salen del marco aportando energía en una búsqueda rítmica. Esa ruptura con lo esperado es uno de los temas centrales de este trabajo y forma el hilo conductor de los tres bloques que constituyen el libro. Cada uno de estas partes o capítulos están escritos por diversos autores: Cristina Manzano Espinosa, Luis Deltell Escolar y Emilio C. García Fernández.

El primer capítulo escrito por la profesora Cristina Manzano se titula «El cortometraje de animación como reflejo de la sociedad contemporánea». En él se observa el cortometraje de animación no como un subgénero menor del audiovisual, sino como un producto artístico pleno. Para argumentar su hipótesis Manzano realiza un recorrido por todas las posibilidades que manifiesta la animación en las obras de breve duración. En la primera parte de su trabajo realiza una indagación sobre los usos educativos del cortometraje de animación, así la autora indica: "Guichot y Rueda señalan tres ventajas del cine como recurso educativo: que el aprendizaje derivado de él es duradero (apoyado por un discurso compuesto de imagen y sonido), que ejerce una atracción sobre el alumnado (por la capacidad de excitar los sentidos de manera conjunta) y que cuenta con un recorrido interdisciplinar (a través de campos que interactúan con el cine, como la psicología, la sociología o la filosofía)» (p. 18).

El cortometraje de animación no es solo un entretenimiento inocente para niños, sino que puede servir con la metodología adecuada en la formación del discente. Algo que nos recuerda las ideas de Víctor Manuel Amar Rodríguez que decía en su libro Comprender y disfrutar el cine: «el cine es un medio que se puede utilizar en el contexto del aula como transmisor de conceptos, actitudes, conductas, valores o contravalores, entre sus muchos usos. Aunque no sólo ha de utilizarse como un mero transmisor, ya que el cine en sí presenta la opción de analizarlo, hacerlo disfrutarlo, compartirlo...e incluso utilizarlo a modo de fórum (debate) [...] el cine es una herramienta para el acto didáctico, entendiéndolo como el arte de enseñar todo a todos» (Amar Rodríguez, 2003, p. 17). De esta forma el cine puede ofrecer herramientas determinantes para la formación pedagógica.

Por otro lado, Cristina Manzano manifiesta: «la intención compartida con la actividad de denuncia o de exposición de intereses contemporáneos es una intención creadora, artística y en una gran parte de los casos, recuperadora de técnicas manuales o artesanales, en las que el proceso puede estar directamente relacionado con la intención del mensaje» (p. 20). Así, la autora explica como los cortometrajes se estructuran inteligentemente en: La identidad, el acoso escolar, la situación social de la mujer, el mundo moderno vs. mundo tradicional y lecciones de vida; de tal manera que el lector puede observar como alguno de los cortometrajes transgreden a la industria de la animación.

Por último, en este primer capítulo, también, se hace referencia al cortometraje de animación en España cuya producción es discreta. Cristina Manzano realiza una clasificación en cuanto a: la identidad (identidad cultural, identidad colectiva, etc.), ecología y futuro, mundo moderno vs. mundo tradicional, lecciones de vida, reconocimiento del valor educativo (el Ministerio de Educación, ciencia y Deporte ofrece material didáctico, perspectivas para ser aprovechadas por los centros educativos). La autora dedica especial interés a mostrar que el cortometraje español de animación recurre a muchas técnicas diversas: perspectivas digitales, el stop motion, técnicas tradicionales (dibujo, pastel, acrílico), etc. 
En el segundo bloque, titulado "Breve cartografía del cortometraje documental en España durante las dos primeras décadas del siglo XXI", Luis Deltell explica cómo el formato breve deviene en un arte mutable y en continua transformación. Estos cambios parecen haberse enfatizado con la aparición de Internet. La tecnología digital y la Red han cambiado la relación entre el autor-creador y el espectador. Así, el cine como espectáculo de masas parece haber mudado a un entretenimiento más individual y privado. En este contexto de cambio, el cortometraje documental (sobre todo en su versión ensayística) es considerado un formato cuestionado por los estudiosos y la crítica. Deltell en la página 110 considera al cortometraje como «toda aquella producción audiovisual que no es un largometraje. Esto permite una gran flexibilidad temporal al género». El cortometraje es un formato breve de escaso o ningún beneficio económico pero que, precisamente, por su precariedad se convierte en un formato versátil y mutable.

Al hablar de cortometraje documental experimental en España se hace referencia a Luis Buñuel y a José Val del Omar. Pero, sobre todo, a partir del siglo XXI a Víctor Erice quien junto a Abbas Kiarostami serán dos de los creadores referentes para los cortometrajistas documentales. El hecho de que dos grandes maestros del cine, con largometrajes multipremiados en todo el mundo, vuelvan a rodar cortometrajes supone un enorme prestigio para el formato breve del documental. Como señala Deltell en la página 122 respecto a Erice: «un cineasta consagrado renuncie -voluntariamente- a las estructuras ficcionadas y acuda al documental supone una ruptura nada frecuente en la tradición cinematográfica; la segunda rotura es que abandona el formato del largometraje para recurrir a modelos más breves, cortometrajes; y la tercera quiebra que nos presenta Erice es que estos filmes dejan de estar pensados para la sala cine».

A continuación, Deltell nos habla de la relación de los cortometrajes con los museos, el paso de la no ficción a la ficción. La influencia de José Luis Guerín en autores como Jonás Mekas. Otro punto para destacar, según este autor, son el de los festivales y el de los premios; especialmente el premio Goya a mejor cortometraje documental. El autor realiza una reflexión de cómo los festivales de cine y los premios nacionales e internacionales han ido construyendo un gusto y una estética para promover el cortometraje documental.

Este nuevo gusto por el formato del cortometraje documental viene acompañado, según Deltell, por el poderoso impacto del ensayo audiovisual. Esta escritura del yo, que mezcla reflexiones personales y estructuras propias de la no ficción encaja a la perfección con la brevedad del cortometraje. Como indica el autor los márgenes del cortometraje documental están muy abiertos porque las posibilidades estilísticas son inmensas.

El último bloque del trabajo lo firma el catedrático recientemente jubilado Emilio C. García Fernández y se titula: «El cortometraje como formato de branded content en la comunicación empresarial. Lo importante es la historia y las experiencias emocionales». En este capítulo se aborda el cortometraje publicitario y destaca que la proyección internacional del cortometraje español es muy importante. La propuesta de García Fernández comienza con un breve viaje por los antecedentes de la publicidad (convencer al espectador) y de las diversas estrategias publicitarias que se han usado hasta llegar a la aparición del cortometraje como recurso del branded content, es decir, crear una historia emocional para publicitar algo. Esta técnica creativa se comenzó a desarrollar a finales del siglo XX, pero es en el siglo XXI cuando más se ha usado en el cortometraje audiovisual español. 
Emilio C. García Fernández, como historiador de cine, hace referencia a los precedentes en el branded content. Así, por ejemplo, en España desde 1950 se han utilizado las celebrities en el sector publicitario para afianzar la credibilidad de un producto, mas no será hasta estos últimos años cuando la producción de branded content logre su mayor difusión. García Fernández plantea varios ejemplos clave en esta nueva estrategia comunicativa uno de ellos es: "El tiempo que nos queda (2018), realizado por Félix Fernández de Castro y la agencia Leo Burnet, es, según el autor, una de las acciones de branded content más impactantes de las que han sido emitidas por televisión y que prolonga su vida en YouTube» (p. 203).

Tres compañías realizarán campañas que perduran en el tiempo y que mantienen un hilo conductor (a veces narrativo o a veces de estilo). Estas empresas son: una del ámbito energético (Gas Natural Fenosa/Naturgy), otra del sector de bebidas (cervezas Damm) y una tercera de alimentación (Campofrío). García Fernández indica que en lo referente a Gas Natural Fenosa/Naturgy, la campaña tiene lugar una comunicación Transmedia. Con respecto a las cervezas Damn se centra en el branded content "Mediterráneamente», Campofrío por su parte se centrará en directores españoles implicados con la sociedad deprimida y enfadada del momento a raíz de la crisis económica. El uso del branded content en pequeño formato muestra, como indica Emilio C. García Fernández, que el cortometraje puede ser una excelente forma de promoción y de publicidad.

Como escribe Cristina Manzano: "A través de los relatos breves, como es el caso del cortometraje, se condensan invitaciones concretas para estimular el pensamiento" (p. 29). Por su capacidad de crear pensamiento, estética y comunicación; el cortometraje debe lograr una parcela propia en la investigación estética del audiovisual. En definitiva, el libro Nuevos márgenes del cortometraje es interesante y, aunque es un texto científico y académico, resulta ameno y agradable en su lectura. Nos ofrece un viaje único a través del cortometraje, una experiencia donde se muestra que los límites y los márgenes de esta forma breve son muy amplios y abiertos. En suma, los tres autores del texto nos proponen conocer mejor los cortometrajes para disfrutarlos más y entender que son un campo de exploración para cineastas donde los márgenes no están definidos.

\section{Bibliografía}

Amar Rodríguez, V.M. (2003), Comprender y disfrutar el cine, Huelva, Grupo Comunicar Ediciones.

Villegas López, M. (1992), El cine en la sociedad de masas, Madrid, Ediciones JC. 